\title{
(MOSAIC MOTIFS STRUCTURE): A PROPOSED STRATEGY IN TEACHING FASHION DESIGN PRACTICAL COURSES
}

\author{
Rehab Ragab Mahmoud Hassaan \\ Prof. Dr. University of Nizwa, OMAN. Helwan University, Egypt \\ rehab.ragab@unizwa.edu.om
}

\begin{abstract}
The Objective of the current study is to investigate effectiveness of using a new strategy which is founded by the researcher and had been called (Mosaic Motifs Structure), proposed strategy appropriates for practical fashion courses such as: hand embroidery, machine embroidery, fabrics dyeing, fabrics printing and painting, textile structure and design, hand weaving, hand crochet and tricot and all hand crafts courses. The proposed strategy (Mosaic Motifs Structure) had been launched through the experience of teaching hand Embroidery course at Nizwa University - Fashion Design Program- Fall semester /2020. The final project of the course -after teaching and learning hand embroidery stitches- was focusing on the main objective of the Fashion Program which is represented in enhancing the creativity skills of designing fashion, the researcher/ course instructor proposed a project of embroidering some cut motifs of felt material, then gather embroidered motifs on a foam mannequin in many designs, selecting the best design or structure, finally attach the embroidered felt motifs together for forming the selected structure by the student/designer producing a unique fashion piece. Thus the project which represents the new proposed strategy (Mosaic Motifs Structure) achieved three main goals, first: verification of accessing embroidering skills for the students as embroidery learners, second: enhancing creativity thinking skills for the students as fashion designers, third: enhancing the employing of the accessed skills in creating unparalleled fashion. The results -executed designs- of the experience had been evaluated through a rating scale and the proposed strategy had been evaluated through a questionnaire. From this point the proposed strategy can be generalized in many other fashion practical courses. The researcher used descriptive and experiment methodologies for the procedures and accessing the statistic results of the study. The study recommends adopting the proposed strategy in teaching practical courses in Fashion Design Programs.
\end{abstract}

Keywords: (Mosaic Motifs Structure) - fashion design program- practical fashion courses- hand embroideryembroidered felt motifs- mosaic motifs fashion- innovative fashion.

\section{INTRODUCTION}

Faculty members are responding to pressures to be more responsive to students' needs and more concerned about how well students are prepared to assume future societal roles. Faculty are already feeling the pressure to lecture less, to make learning environments more interactive, to integrate technology into the learning experience, and to use best learning strategies when appropriate. Some of the more prominent strategies are lecture, case method, discussion, active learning, cooperative learning, integrating technology and distance learning. The researcher as a teacher of fashion design courses for 25 years already used many of these mentioned strategies and more, through the experience of teaching (Hand Embroidery) at University of Nizwa - College of Arts and Sciences- Department of Education and Humanities Culture- Fine 
Art Program- Speciality of Fashion Design- First/ Fall Term 2019/ 2020 the researcher/ professor of the course reached to a new strategy, named it "Mosaic Motifs Structure".

Strategy, in general can be defined as the use of means to achieve goals, meaning that the strategy is a framework guiding the method of work and a guide to its movement. The teaching strategy is defined as regular and sequential procedural steps that are comprehensive, flexible and consider the nature of the learners, as well as taking the available capabilities into account, with the aim of achieving the desired learning outcomes. "A teaching strategy is the method you use to convey information to your students." (Goodwin, 2018).

A good strategy has specifications, namely: the comprehensiveness of all possibilities of the educational situation - flexibility as it can be used in other classes - its relevance to the objectives of teaching - taking into account the individual differences between the learners - taking into account the capabilities available at the university. And it includes a group of ingredients, which are: Teaching objectives - teacher steps - used methods - educational atmosphere and finally the students' response.

The current study aims to establish an innovative strategy in teaching practical courses of fashion design programs, to be achieved through the proposed strategy: skills development - the development of creative and critical thinking - the encouragement of experiential learning and producing of innovative fashion.

\section{OBJECTIVES}

The study aims to establish a new strategy for teaching practical courses in fashion design programs, so that this strategy achieves three main objectives:

1- Verifying the acquisition of basic skills in the Hand-Embroidery course.

2- Enhancing students 'innovative thinking skills as fashion designers.

3- Producing innovative fashion.

\section{SIGNIFICANCE}

1- Developing new teaching strategies would develop the educational process generally.

2- The proposed strategy can be applied in other programs specialized in teaching Design Programs.

3- The new proposed strategy "Mosaic Motifs Structure" benefits also fashion designers in producing unprecedented fashion with many perceptions.

\section{HYPOTHESIS}

1-The different practical skills of Hand Embroidery Course can be inserted into the production of Several miniature cut motifs' successfully.

2-Innovative fashion can be produced through cut motifs composition, named Mosaic Motifs Structures.

3-The teaching strategy named (Mosaic Motifs Structure) can be established to teach Hand Embroidery for the students of the Fashion Design program.

4- (Mosaic Motifs Structure) Strategy can be applied to many practical courses in fashion design programs to achieve three objectives: Application of the course skills - Development of students' innovative thinking as designers - Production of innovative fashion.

\section{METHODOLOGY AND INSTURMENTS}

Descriptive Approach, in designing study instruments: - a scale for evaluating student production (Rating Scale of Mosaic Motifs structures Fashion) - a questionnaire for the opinions of faculty members specialized in Fashion Design - establishing the principles for the proposed strategy (Mosaic Motifs Structure)

Semi-experimental approach: When applying the strategy on a sample of (24) students, first semester / Fall 2019/2020 at the University of Nizwa.

\section{RELIABILITY AND VALIDITY OF THE INSTURMENTS}

\section{1- (Rating Scale) to Evaluate Students' Artworks -Fashion Pieces- in the Study Experiment}

(Rating Scale) had been designed by the researcher on two axes that include (12) statements, (3) for the first axis and (9) for the second axis. The reliability of the scale was verified by presenting it to a group of supervisors, and then the scale was put in its final form. The validity of the scale was confirmed by 
Cronbach's alpha as 0.95 , which confirms its validity for application. The scale and the students' work were presented to a group of faculty members specializing in fashion, design and arts, and the evaluating was measured by Likert's five-point scale, so that the highest score for the scale is (60) and the lowest score is (12).

\section{2- Opinions Questionnaire of Faculty Members in the Proposed Strategy}

A Questionnaire had been designed by the researcher on two axes that include (10) statements, (5) for the first axis and (5) for the second axis. The reliability of the questionnaire was verified by presenting it to a group of supervisors, and then the questionnaire was put in its final form. The validity of the questionnaire was confirmed by Cronbach's alpha as 0.90 , which confirms its validity for application. The evaluating was measured by Likert's five-point scale, so that the highest score for the questionnaire is (50) and the lowest score is (10).

\section{THE STUDY SAMPLE}

The study sample consisted of: (24) female students in the fashion design program - (7) faculty members in fashion design speciality - (11) faculty members in curricular sciences and teaching methods.

\section{THEORETICAL FRAMEWORK}

\subsection{Strategy and Teaching Strategy}

\subsubsection{Strategy}

The strategy is to use the available resources, materials and means in the best way to achieve the desired goals, (1) When we try to achieve some objectives by any method it becomes strategies; (2) strategy is actually a combination of different method; (3) for E.g. Lecture or textbook or question answer method can be never be used separately; (4) it is a macro approach; (5) it considers teaching as science; (6) its purpose is to create conducive learning environment; (7) it is based on modern theories of organization; (8) (predetermined objectives, becomes strategy); (8) behaviour of students and teachers and their mutual relationship. (Sputra, Abdul Aziz, 2014. 114)

\subsubsection{Teaching Strategies}

Also known as instructional strategies are methods that teachers use to deliver course material in ways that keep students engaged and practicing different skill sets. An instructor may select different teaching strategies according to unit topic, grade level, class size, and classroom resources. Many learners of instructional strategies are employed to achieve teaching and learning goals and support different kinds of students. Specific strategies can also be employed to teach specific skills. (Kathy, 2020)

\subsection{3 "Mosaic Motifs Structure" as a teaching Strategy}

It is an educational activity that is particularly concerned with preparing students of fashion design programs to create new fashion through their various practical courses. This teaching strategy relies on:

- Interest in thinking and imagining (developing an imaginary picture of the final design based within the mosaic motifs.

- Flexibility in implementation (accepting alternatives in plastic solutions and different proposed forms).

- Sharing with Colleagues (More than one student with their mosaic motifs can participate in the producing of one fashion piece).

\subsubsection{The proposed Strategy for Practical Courses is as Follows}

- Choosing a theme for the applied project through discussion between the instructor and the students.

- Each student selects some basic skill techniques in the course through a free choice of techniques, tools and materials, then apply these skills or techniques in small pieces. (In the current study, the techniques mean the hand embroidery stiches)

- The instructor exchanges the mosaic motifs among the students and assigns them to create innovative designs by forming on the foam Mannequin with pins.

- The instructor encourages the students to create unprecedented designs.

- Students analyze and critique each other's designs. 
- At the end, each student gets back his/her cut motifs, makes a final design with his/her own personal vision, and fixes the motifs beside each other by hand sewing or machine, as mosaic pieces.

-Displaying the students' work at the end of each semester / every practical course in a collective exhibition.

\subsection{Fashion Design Program}

At University of Nizwa, College of Arts and Sciences, Education and Humanities Culture Department, Fine Art Specialty, Fashion Design Program is a program of (132) credit hours, divided to (27) CR hours University requirements/ selection, (20) CR hours College requirements/ selection, (19) CR hours Educational requirements, (66) CR hours Major requirements/ selection. Course of (Hand Embroidery) is one of the major requirements of fashion Design courses.

Fashion Design Program has (10) main outcomes, five of them related to the skills development, means practical parts of the courses have to saturate these objectives and achieve these achievements. The skills outcomes as following:

-The student able to master technical skills and employ them in artistic works.

-The Students can use different types of tools, materials and techniques to produce a successful fashion.

-The student employs different types of artistic attitudes in building innovative artworks.

-The student can describe, critic and analyze the artistic values.

-The student uses various research resources and databases of information in the applications of technologies related to the fashion field. (University of Nizwa bylaw)

\section{3 (Hand Embroidery) Course}

The course is divided into two parts. The first is theoretical. It includes the study of hand embroidery history and the study of embroidery on different traditional costumes, including the Omani traditional costumes for men and women. And the applied part includes the basic set of stitches as follows: running stitch- back stitch- satin stitch- stem stitch- seed stitch- chain stitch- fishbone stitch- Cretan stitch- blanket stitch- long\& short stitch. And embroidery with additions, such as embroidery with pearls, crystal, buttons and plastic, wooden and metal beads. The course professor also allowed the students to add some innovative stitches in the applied projects.

\section{4. "Mosaic Motifs Structure" as a fashion strategy}

\subsubsection{Why Mosaic? Why Motifs?}

Mosaic is a picture or pattern produced by arranging together small pieces of stone, tile, glass, etc. Motif is a decorative image or design, especially a repeated one forming a pattern. (Oxford Languages and Google). What is meant by the term is: designing a mini motif from cut felt fabric then embroider the mini motif with different types of stitches, repeat this process with many motifs with different shapes, colours and stitches. Consider these stitched motifs as mosaic pieces and place them next each other to design a one fashion piece.

\subsubsection{The strategy of "Mosaic Motifs Structure" Considerations}

The proposed strategy of "Mosaic Motifs Structure" in the current study for teaching practical courses of fashion design programs depends on five considerations:

First: The goal of teaching fashion program students some of the skills associated to fashion design such as printing, embroidery, dyeing and others is widening the student's skills of the possibility of benefiting from the applications of these art courses in the field of fashion. Rather, they are linked to fashion design to a large extent.

Second: The fashion designer is not required to produce any products but fashion pieces through learning these courses, not table linens, scarves, Curtains, or any products, but fashion pieces.

Third: After learning the basics of skills in these courses, it is possible to employ those basics in developing innovative thinking of designing unprecedented fashion.

Fourth: Each or some of the motifs in a mosaic structure contains the skills that the student must master in the course.

Fifth: mosaic technique is based on dealing with many repeated miniature motifs to construct and implement 
a piece of fashion which is formed on a foam mannequin.

Therefore, this strategy tests the student's capacity to practice course skills and at the same time helps the student directly to employ these skills in producing an innovative fashion, thus enhancing the student's personality as an innovative fashion designer after graduation.

\subsubsection{Principles of Fashion Structure within Mosaic Motifs}

There are some principles of the fashion composition within Mosaic Motifs Technique, (unity), (harmony), (rhythm) and (proportion) comes automatically because of using one theme for all mini motifs, there are some other basics should be put into account, as following:

- Dominate \& Subordinate: When one or more of the design elements are emphasized measurably more than any others, they are dominant (have the greatest visual weight, greatest number, or has the most influence). When dominant/subordinate is used together, they create stability and order. Subordination is simply any of the elements that are emphasized less than the dominant ones

- Repetition with Variation: Repetition means to repeat one or more of the motifs to build the design structure. Variation means to change one or more of the motif's shapes.

-Overlapping: is when shapes are in front of other shapes. Two principle outcomes of overlapping shapes within a composition are: 1) make shapes either dominant or subordinate and 2) to vary and repeat the shape.

- Balance: Refers to the way the motifs are arranged in mosaic structure, within the format to create a feeling of stability or harmony. When considering the idea of balance, it is very helpful to divide any composition in half, using a central illusion line. If the shapes are mostly the same on each side of this line, the composition is symmetrical. If they are different on each side of the central line, they are asymmetrical. (Bradely, 2018, P.209: 259)

Contrast: as a principle of composition, differentiates line, value, shape, texture, and colour. It helps to create dominant areas, emphasizing what is most important. Contrast makes shapes clearer. In current project of embroidered felt units, the students used the principle of contrast in selecting felt colours and threads colours.

- Alignment: As a principle of composition, is used to help place or organize the shapes within the format and give it a unified structure, for example shapes are placed horizontally and vertically, above and below each other, to help create stable and consistent structure. (Lidwell, Holand, Butler, 2003, P.22:39)

- Superposition: When installing a small unit or motif on top of another larger unit.

- Gradation: Scaling is the sizes between large and small of the motifs Component of the design.

- Focal Point: The focus of the vision in the implemented fashion design should be directed to the parts of applying the course skills.

\section{EXPERIMENTAL FRAMEWORK}

The researcher in this experience depends on articulating the experimental side indicating the objectives, procedures and application analysis. The main objective of this experiment is to find out a new strategy which can be applied in all practical courses of Fashion Design Program and measure the experiment outcomes.

\subsection{Felt Fabric}

Felt is a non-woven fabric composed of interlocked fibres. There are two main types of felt, first: pressed felt, which is produced by applying heat moisture and friction to entangle and bind fibres together, second: needle felt, which mechanical operation plays the main role to interlock the fibres together. Therefore felt can be cut without fraying. (Atifi, 2016,) Felt can be made with both natural fibres, such as wool, and synthetic fibres like acrylic and polyester. In general, pressed wool felts are considered the highest quality of felt fabric. (Ammayappan, Moses, Shunmugam. 2006. P. 617)

Felt can be obtained in various lengths, widths and thicknesses. The current project used the felt sheets which is commonly available in a wide spectrum of colours. Felt retains water and other liquids. Felt is also durable and resistant to wear and tearing. (Giles, 2010, P.5) (Houghton, 2018, P13)

A non-woven fabric felt holds its edges and will not unravel when cut. These advantages, along with its naturally beauty and versatility, make felt the perfect material for the designer and crafter. In fact, felt is well 
suited for use in every sector and the researcher found it the perfect fabric for experiencing the "Mosaic Motifs Structure" in (Hand Embroidery) course.

\subsection{Felt/Mosaic Motifs Cut Patterns}

\subsubsection{Experiment Constants and Variables:}

Although there are many felting techniques and patterns of construction to create unique fashion pieces through felt, from simple scarves through hats to jackets and coats, but the applied project of the current study is concentrating on making, practicing and designing creative fashion corsages through embroidering the felt cut motifs/patterns. The instructor/researcher guided the students to select some shapes of the patterns, including (geometric shapes- natural abstracted shapes as leaves- Omani traditional motifs).

The experimental activity was carried out in this study depending on a set of constants and variables, which represent the limits of the practical experiment. As follows:

Table 1: Lego Fashion experiment constants and variables

\begin{tabular}{|c|c|}
\hline Experiment constants & Experiment variables \\
\hline $\begin{array}{c}\text { - Using } 2 \mathrm{~mm} \text { felt material as a basic material for } \\
\text { embroidery and building mosaic motifs structures. } \\
\text {-The types of used stitches are the included ones in } \\
\text { the course, in addition to allowing the student to } \\
\text { implement innovative stitches. }\end{array}$ & $\begin{array}{c}\text { - Colours and shapes of the mosaic motifs. } \\
\text {-Formation style (superposition- overlapping- } \\
\text { contrast- alignment- grading increase and } \\
\text { decrease- and other principles) }\end{array}$ \\
$\begin{array}{c}\text {-Forming the embroidered motifs as a corsage on } \\
\text { the foam mannequin, then choosing the best } \\
\text { formation at the end gather the motifs in mosaic } \\
\text { structure. }\end{array}$ & \\
\end{tabular}

\subsubsection{Experiment Sample}

(24) Students of Hand Embroidery Course- fashion Design Program- Education and Humanities Culture Department- College of Arts and Sciences- University of Nizwa - Sultanate of Oman.

First / Fall semester 2019/ 2020.

\subsubsection{Experiment Procedures (classroom strategy steps):}

-Each student selects a set of shapes, and then chooses the colors and cuts out the felt patterns -supervised by the instructor/researcher. (theses patterns represent the mosaic motifs of the fashion design after embroidery stitching).

-The student designs and creates embroidery stitches on each shape separately- supervised by the instructor.

- The instructor redistributes motifs among students, asking for forming a corsage on the foam mannequin by each student.

-The instructor open discussion among the students/ designers about their creations.

- Each student restores his/her own miniature mosaic motifs and compose the fashion piece on the private taste.

-The student pins the motifs on the foam mannequin.

-The student selects the best composition and attaches the embroidered motifs with each other in a whole mosaic structure.

\subsection{Hand Embroidery Stitches}

The theoretical part of the course includes embroidery history and samples of embroidered traditional costumes, practical part includes training of making some stitches, divided into:

- Classic basic stitches (running stitch- back stitch- satin stitch- stem stitch- seed stitch- chain stitch- fishbone stitch- Cretan stitch- blanket stitch- long\& short stitch). 
- Embroidery with pearls, buttons and crystal beads

-New creative stitches form y the student, which is matching with the shape of cut shape.

\subsection{The creative fashion corsage (Mosaic Motifs Structure)}

Includes "Fig.1" to "Fig. 12" which represents some samples of the students Mosaic Motifs Fashion within the current experiment of the proposed strategy "Mosaic Motifs Structure"
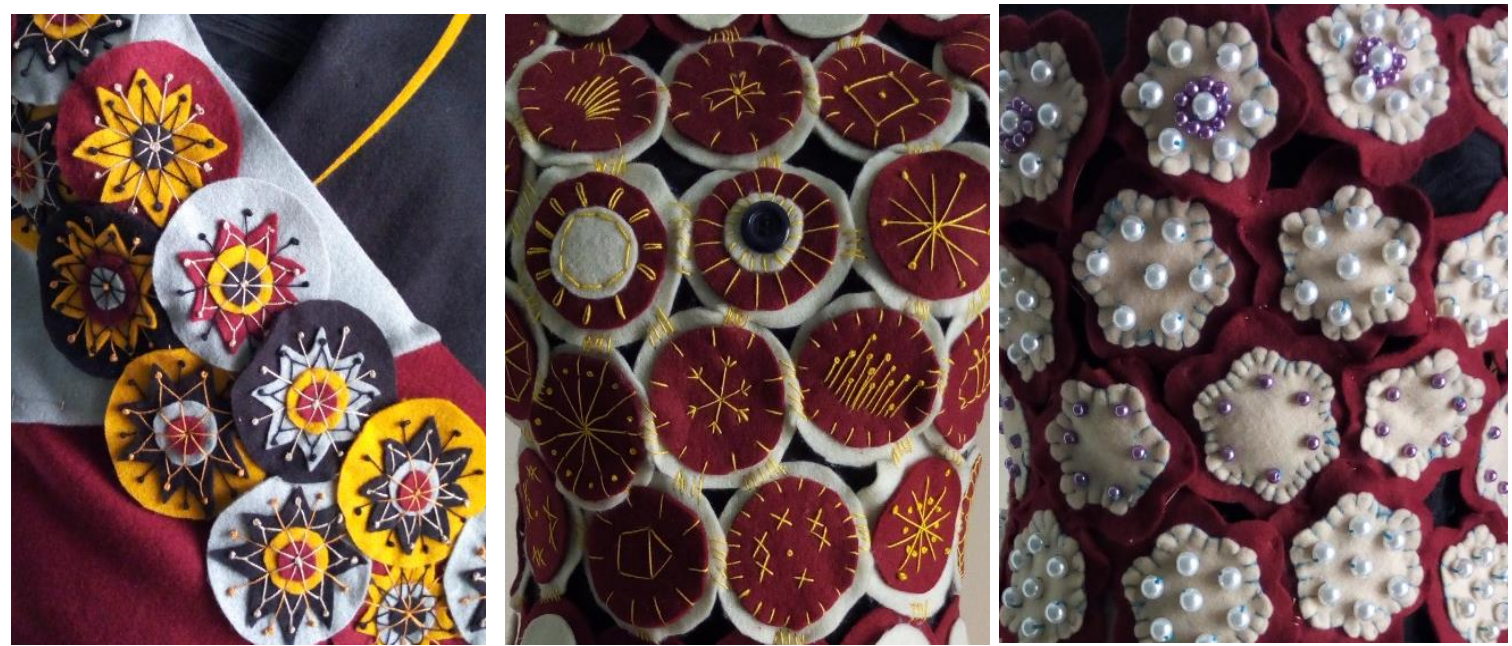

Fig. 1. 2. 3: Different hand embroidery stitches attached together in (Mosaic Motifs Structure) applying the strategy basics of Mosaic Motifs Fashion: superposition- overlapping- alignment-gradation- repetition.

Hand embroidery stitches: blanket stitch- pearl embroidery- innovative stitches by the students.
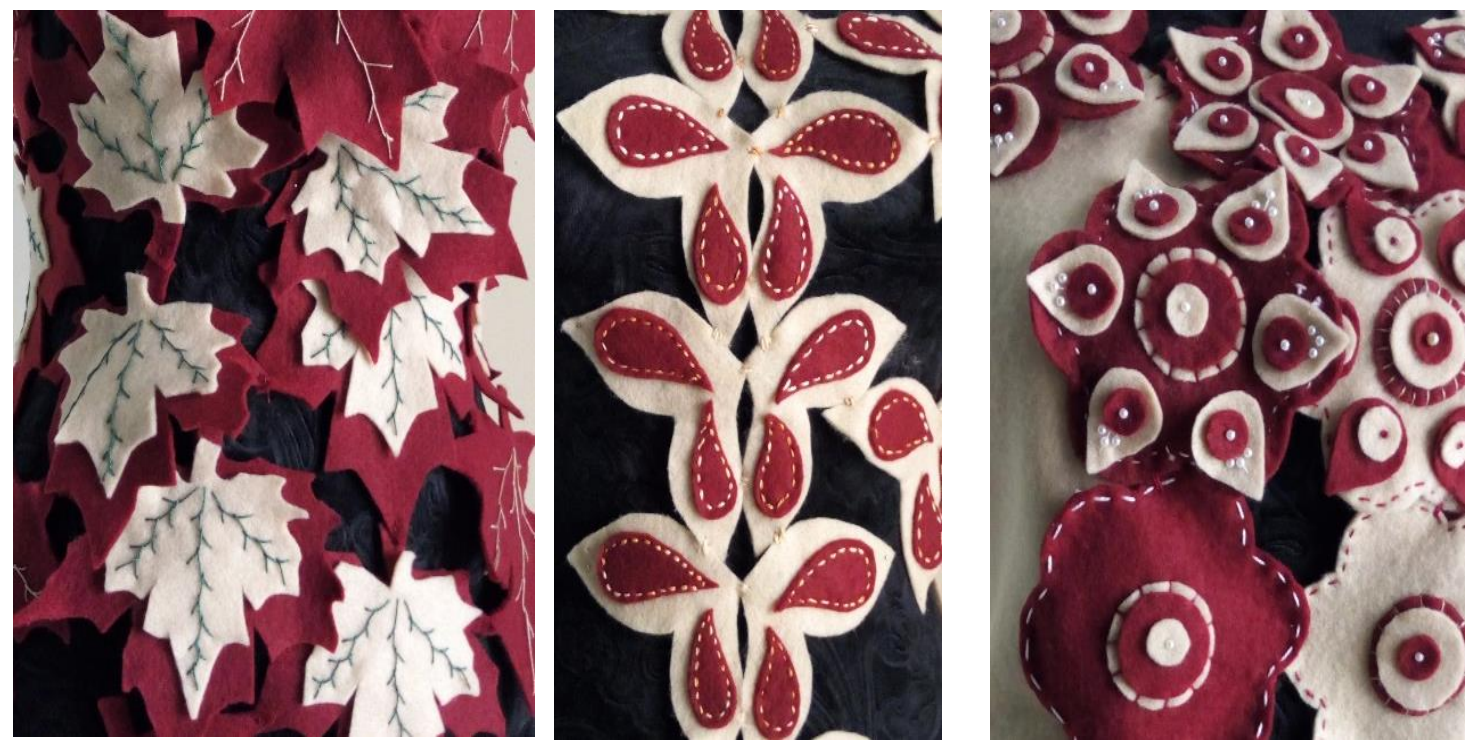

Fig. 4.5.6: Different hand embroidery stitches attached together in (Mosaic Motifs Structure) applying the strategy basics of Mosaic Motifs Fashion: superposition- overlapping- alignment-gradation- repetition.

Hand embroidery stitches: running stitch- pearl embroidery- Cretan stitch- blanket stitch. 

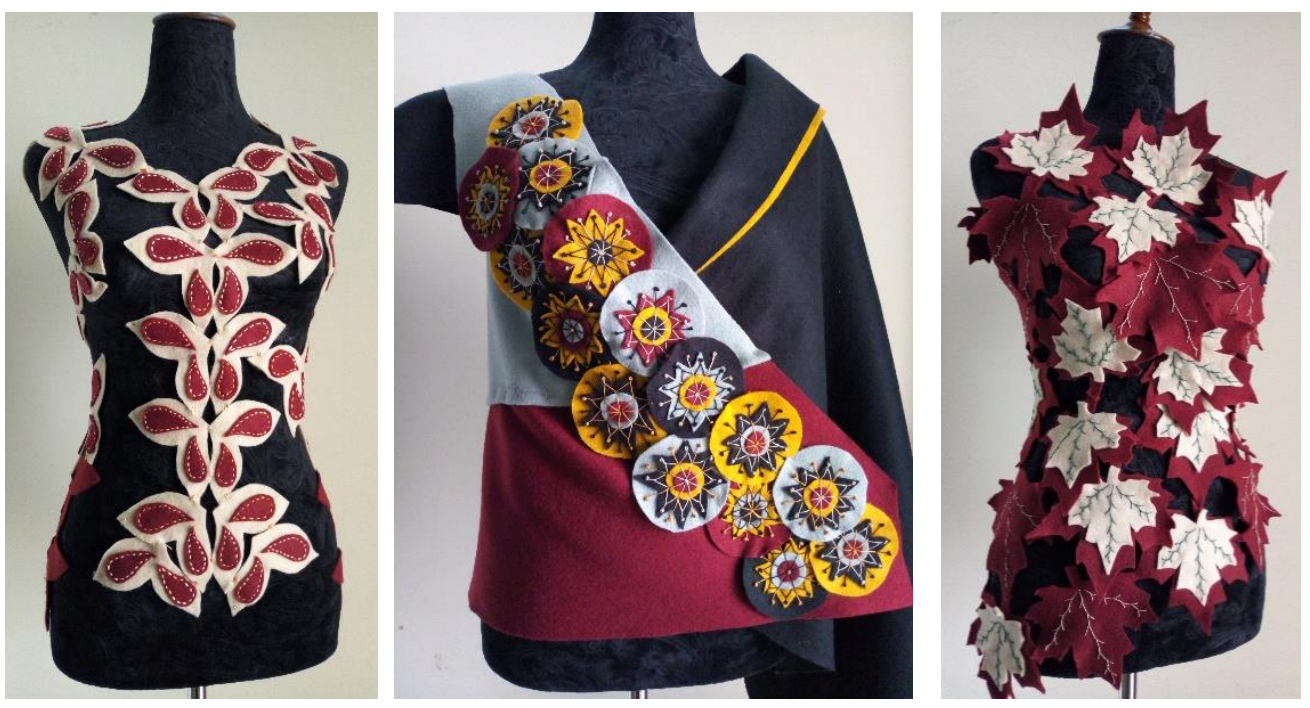

Fig. 7. 8. 9: Fashion Program students' projects of Hand Embroidery Course following "Mosaic Motifs Structure" strategy
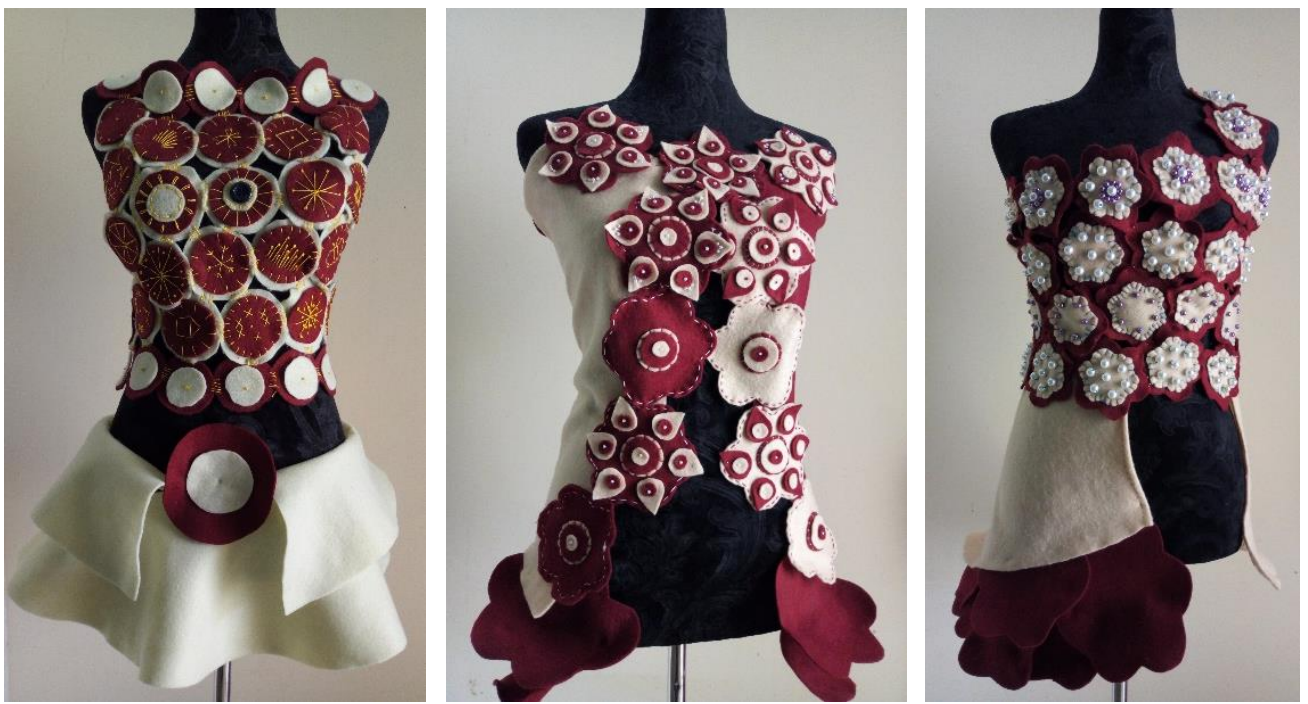

Fig. 10. 11. 12: Fashion Program students' projects of Hand Embroidery Course following "Mosaic Motifs Structure" strategy

\section{THE STUDY RESULTS}

First hypothesis: "The different practical skills of Hand Embroidery Course can be inserted into the production of Several miniature cut motifs' successfully. ". First axis of the Rating Scale represents the responding, as follows:

Table 2. Rating Scale: First axis: Aesthetics of one Lego unit

\begin{tabular}{|c|c|c|}
\hline \multicolumn{1}{|c|}{ Phrase } & (SMA) & Proportion \\
\hline$-\begin{array}{l}\text { The single motif of the mosaic structure which consists the design } \\
\text { is a miniature model/pattern of applying practical skills of the } \\
\text { course (Hand Embroidery) }\end{array}$ & 4.32 & $86.4 \%$ \\
\hline $\begin{array}{l}\text { A single motif is a miniature artwork that includes design elements } \\
\text { (point - line - colour - area - material - texture ...) }\end{array}$ & 4.02 & $80 \%$ \\
\hline $\begin{array}{l}\text { The single motif is a miniature artwork that achieves the } \\
\text { composition principles (unity - balance - rhythm - proportion - } \\
\text { contrast - compatibility ...) }\end{array}$ & 4.55 & $91 \%$ \\
\hline \multicolumn{1}{c}{ Total } & 4.29 & $85.93 \%$ \\
\hline
\end{tabular}

Second hypothesis: "Innovative fashion can be produced through cut motifs composition, named Mosaic 
IJAEDU- International E-Journal of Advances in Education, Vol. VI, Issue 18, December, 2020

Motifs Structures ". Second axis of the Rating Scale represents the responding, as follows:

Table 3. Rating Scale: Second axis: Fashion within Lego Building Technique

\begin{tabular}{|c|c|c|}
\hline Phrase & (SMA) & Proportion \\
\hline $\begin{array}{c}\text { - Mosaic Motifs Fashion fulfils the principle of (Dominate and } \\
\text { Subordinate) }\end{array}$ & 4.13 & $82.6 \%$ \\
\hline $\begin{array}{c}\text { Variation) } \\
\text { - Mosaic Motifs Fashion fulfils the principle of (Repetition with }\end{array}$ & 4.56 & $91.2 \%$ \\
\hline - Mosaic Motifs Fashion fulfils the principle of (Overlapping) & 4.25 & $85 \%$ \\
\hline - Mosaic Motifs Fashion fulfils the principle of (Balance) & 4.7 & $94 \%$ \\
\hline - Mosaic Motifs Fashion fulfils the principle of (Contrast) & 4.9 & $98 \%$ \\
\hline - Mosaic Motifs Fashion fulfils the principle of (Alignment) & 5 & $100 \%$ \\
\hline - Mosaic Motifs Fashion fulfils the principle of (Superposition) & 4.66 & $93.2 \%$ \\
\hline - Mosaic Motifs Fashion fulfils the principle of (Gradation) & 4.3 & $86 \%$ \\
\hline - Mosaic Motifs Fashion fulfils the principle of (Focal Point) & 4.1 & $82 \%$ \\
\hline Total & 4.51 & $90.2 \%$ \\
\hline
\end{tabular}

Third hypothesis: "The teaching strategy named (Mosaic Motifs Structure) can be established to teach Hand Embroidery for the students of the Fashion Design program. ". First axis of the questionnaire represents the responding, as follows:

Table 4. Strategy Questionnaire Measurement: First axis: The proposed Strategy Properties

\begin{tabular}{|c|c|c|}
\hline Phrase & (SMA) & Proportion \\
\hline $\begin{array}{c}\text { The strategy is matching with the objectives of the course (Hand } \\
\text { Embroidery) }\end{array}$ & 4.25 & $85 \%$ \\
\hline $\begin{array}{c}\text { - The proposed strategy is inclusive for different educational } \\
\text { situations }\end{array}$ & 4.56 & $91.2 \%$ \\
\hline $\begin{array}{c}\text { - The strategy is flexible and can be used in more than one } \\
\text { classroom }\end{array}$ & 4.63 & $92.6 \%$ \\
\hline $\begin{array}{c}\text { The strategy considers the individual differences between the } \\
\text { learners }\end{array}$ & 4.65 & $93 \%$ \\
\hline - The strategy considers the capabilities available in universities & 4.35 & $87.1 \%$ \\
\hline Total & 4.49 & $89.76 \%$ \\
\hline
\end{tabular}

Fourth hypothesis: "(Mosaic Motifs Structure) Strategy can be applied to many practical courses in fashion design programs to achieve three objectives: Application of the course skills - Development of students' innovative thinking as designers - Production of innovative fashion. ". Second axis of the questionnaire represents the responding, as follows: 
Table 5. Strategy Questionnaire Measurement: First axis: The Implemented fashion through the proposed strategy (Lego building technology)

\begin{tabular}{|c|c|c|}
\hline Phrase & (SMA) & Proportion \\
\hline $\begin{array}{c}\text { - Designing and implementing the Corsage is a unique application of } \\
\text { the practical skills of the course (Hand Embroidery) }\end{array}$ & 4.55 & $91 \%$ \\
\hline - The implemented corsage is an innovative fashion design piece. & 4.65 & $93 \%$ \\
\hline $\begin{array}{c}\text { - The proposed strategy (Mosaic Motifs Structure) enhances } \\
\text { innovative thinking of the fashion program students }\end{array}$ & 4.28 & $85.6 \%$ \\
\hline $\begin{array}{c}\text { The proposed strategy can be applied in more than one practical } \\
\text { course, as fabric printing and fabric dying courses. }\end{array}$ & 4.56 & $91.2 \%$ \\
\hline $\begin{array}{c}\text { The experiment and proposed strategy can be applied in all fashion } \\
\text { design programs. }\end{array}$ & 4.27 & $85.4 \%$ \\
\hline Total & 4.46 & $89.2 \%$ \\
\hline
\end{tabular}

\section{RECOMMENDATIONS}

The current study recommends adopting the proposed strategy (Mosaic Motifs Structure) in teaching practical courses in fashion programs such as printing, dyeing and drawing on fabric courses, textile compositions and machine embroidery courses, and all handicraft courses, because the results have demonstrated the ability of the proposed strategy to: 1- Developing the skills targeted in the course.

2- Enhancing students' innovative thinking as fashion designers. 3- Producing innovative fashion pieces.

\section{ACKNOWLEDGEMENT}

This research was applied at University of Nizwa.

Appreciation to my students for their positive response during the project experiment.

Prof. Dr. Ruth Mateus-Berr for her important opinion in naming the proposed strategy.

\section{REFERENCE LIST}

Ammayappan, L. Moses, J. Shumugam, V. (2006). An Overview of the production of Nonwoven Fabric from Woolen Materials. Textile Research Journal, Vol 67, no8, PP 616: 618.

Atifi, L. (2016) .Felt and its properties". June, 27.

From: http://www.lilylatifi.com/en/news/flexible-materials/felt-and-its-properties. (11August 2020)

Bradely, S. (2018). Design Fundamentals: Elements, Attributes and Principles. Vanseo Design. Boulder. Colorado.

Giles, J.: (2010). Felt Fashion: Couture Projects from Garments to Accessories. Quarry Book.

Goodwin, J. (2018) top 10 Teaching Strategies to use in your Classroom. Magoosh.

From: https://schools.magoosh.com/schools-blog/top-10-teaching-strategies (16 August 2020)

Houghton, L. (2018). Felt Fashion: Creative and Inspirational Techniques for Felt Makers. Batsford. London.

Kathy, s. "What are teaching strategies". Effective Teaching Strategies.

From:https://study.com/teach/instructional- 
strategies.htm|\#: :text=Teaching\%20strategies\%2C\%20also\%20known\%20as,and\%20practicing\%20 different\%20skill\%20sets.\&text=Specific\%20strategies\%20can\%20also\%20be,like\%20strategies\%20f or\%20problem\%20solving. (12August 2020)

Lidwell, W. Holden, K. Butler, J. (2003). Universal Principles of Design. Library of Congress. USA.

Oxford Languages and Google: From: https://languages.oup.com/google-dictionary-en/

Saputra, J. B. Abdul Aziz, M. S. (2014). Teachin Strategies.

From: https://www.researchgate.net/publication/327433965_TEACHING_STRATEGIES (13 August 2020)

University of Nizwa bylaw. College of Arts and Sciences. Department of Education and Humanities Culture. 